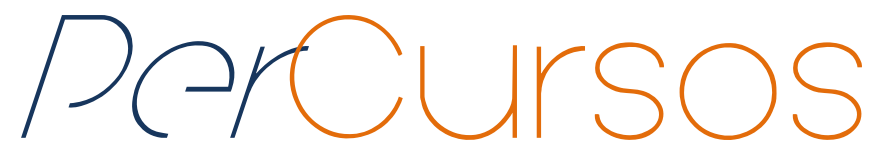

\title{
Ofício como poética: o coordenador pedagógico e os desafios da consolidação de ações político-pedagógicas na escola
}

\begin{abstract}
Resumo
Este texto elege como escopo temático a atuação do coordenador pedagógico perante os desafios inerentes à instituição da cultura pedagógica colaborativa e coletivizada no âmbito escolar. Busca-se enfatizar a "natureza" estético-pedagógica do trabalho coletivo na escola, seus efeitos sobre a potencialização da aprendizagem dos estudantes, e, sobretudo, a legitimação das dimensões político-pedagógicas humanizantes no ofício do coordenador pedagógico. A reflexão aqui apresentada tem como ponto de partida a análise de dados obtidos por intermédio de questionários respondidos por professores e também por meio da observação de práticas pedagógicas. Trata-se do resultado de um Projeto de Intervenção realizado em uma escola da Rede Pública Estadual de Santa Catarina (SC), nos anos de 2013.2 e 2014.1. Das sínteses explicativas construídas no curso do projeto, destacam-se: as resistências e dificuldades dos professores em trabalhar de maneira interdisciplinar e coletiva; os dilemas e insuficiências teórico-metodológicos referentes aos "fazeres" do coordenador pedagógico; e os indicativos efetivos que anunciam a possibilidade de se (re)pensar o ofício deste profissional como poética humanizante (criação de laços e/ou pontes inter-humanas) em oposição aos imperativos técnico-burocráticos preponderantes no atual cenário da referida escola.
\end{abstract}

Palavras-chave: Coordenação pedagógica; Trabalho coletivo; Mediação; Humanização.
Adriana Aparecida Diniz Sanches Especialista em Coordenação

Pedagógica pela Universidade Federal de Santa Catariana UFSC. Professora da Rede Estadual de Ensino do Estado de Santa Catarina. Brasil

adriguidi2011@hotmail.com

\section{Rogério Machado Rosa}

Doutor em Educação pela Universidade Federal de Santa Catarina - UFSC. Professor da Universidade do Sul de Santa Catarina - UNISUL e Técnico em Educação na Universidade do Estado de Santa Catarina UDESC. Brasil

rogeriomachado6@yahoo.com.br

\section{Para citar este artigo:}

SANCHES, Adriana Aparecida Diniz; ROSA, Rogério Machado. Ofício como poética: o coordenador pedagógico e os desafios da consolidação de ações político-pedagógicas na escola. Revista PerCursos, Florianópolis, v. 17, n.34, p. 91 - 111, maio/ago. 2016.

\section{DOI: $10.5965 / 1984724617342016091$}

http://dx.doi.org/10.5965/1984724617342016091 


\title{
Office as poetic: the pedagogical coordinator and the challenges consolidation of political and educational activities at school
}

\begin{abstract}
This text chooses as thematic scope the work of the pedagogical coordinator in facing the challenges inherent in the institution of collaborative and collectivized pedagogical culture in schools. The aim is to emphasize the "nature" aesthetic-pedagogical collective work at the school, its effects on the enhancement of student learning, and especially the legitimacy of the affective-humanizing dimensions craft pedagogical coordinator. The reflection presented here has as its starting point the analysis of data obtained through questionnaires answered by students, teachers and the community, and also through observation of teaching practices.This is the result of an intervention project conducted at a school State Public Network in Santa Catarina (SC), in the years of 2013.2 and 2014.1. The explanatory syntheses built in the project course, stand out: the resistance and difficulties of teachers to work in an interdisciplinary and collectively; dilemmas and theoretical and methodological shortcomings related to the "doings" of the pedagogical coordinator; and actual indicative announcing the possibility of (re) think the craft this professional as poetic humanizing (creation of links and / or inter-human bridges) as opposed to technical and bureaucratic imperatives prevailing in the current scenario of that school.
\end{abstract}

Keywords: Educational Coordination; Collective work; Mediation; Humanization. 


\section{Introdução}

"Grande, no homem, é ser ele uma ponte e não um objetivo: o que pode ser amado, no homem, é ser ele uma passagem, uma corda sobre abismo: uma flecha que anseia pela outra margem." (Nietzsche)

A poética do (com)viver reside nos intercâmbios afetivos, nos elos humanizantes, nas ideias entrelaçadas e na legitimação da alteridade em nome de um objetivo comum: a estetização da existência. Estetização esta que consiste na busca pela afirmação de uma vida mais potente para todos e todas. Persistir no embelezamento da existência implica, necessariamente, em tomar a vida como obra de arte. Nesse sentido, ao embrenharmonos no texto de Nietzsche (1986), em que ele afirma que grande no homem é ser ele uma ponte e não um objetivo, metaforicamente, podemos relacionar tal ideia à figura do coordenador pedagógico. Isso porque o artesanal e singular trabalho deste profissional parece consistir, basicamente, na criação de pontes político-pedagógicas e afetivas com os sujeitos escolares. No cotidiano da escola seus mais caros compromissos residem na abertura de passagens (inter)humanas, na construção de caminhos e acordos didáticopedagógicos, no fomento do desejo de aprender e de ensinar, no incentivo à solidariedade mútua e na criação de laços sensíveis entre os sujeitos que pela escola passam. Trata-se de um ofício poético por excelência: lançar e ser flecha que anseia a outra margem do abismo, do rio, do ser, da existência. Assim, assinalamos que este artigo resulta de uma pesquisa realizada ao longo do Curso de Especialização em Coordenação Pedagógica, promovido pela Universidade Federal de Santa Catarina - UFSC. A pesquisa efetivou-se em uma escola pública estadual do Meio Oeste Catarinense, tendo como ponto de partida a seguinte questão: "Como superar o desafio do trabalho coletivo articulado pelo coordenador pedagógico?”. O tema estava vinculado aos resultados da aplicação de um Projeto de Intervenção (PI) no referido contexto escolar.

\footnotetext{
${ }^{1} \mathrm{O}$ objetivo geral do PI ficou assim delineado: contribuir para a melhoria no ensino-aprendizagem dos alunos da escola " $X$ " por meio da mediação e articulação da coordenação pedagógica. Já os objetivos específicos foram dispostos na seguinte sequência: 1) Refletir sobre as funções e atribuições do
} 
Em nossas observações participantes, vinculadas ao PI, percebemos significativa dificuldade e muitos desafios enfrentados pelos coordenadores pedagógicos no exercício da mediação das práticas pedagógicas no âmbito da coletividade escolar. Principalmente no que diz respeito à instituição de uma cultura pedagógica colaborativa e participativa. Assim, ficou caracterizada a necessidade de um estudo mais aprofundado sobre a temática com o intuito de construirmos reflexões geradoras de sínteses explicativas sobre os dilemas e obstáculos vividos pelos coordenadores pedagógicos no urdimento diário do seu ofício. Também nos propusemos, junto aos coordenadores e a partir dos indicadores obtidos por meio do PI, a fomentar possibilidades de superação dos problemas encontrados. Reiteramos que os indicadores produzidos na pesquisa guiaram e alimentaram a empreitada que assumimos.

Tratou-se, portanto, de uma pesquisa interessada, num dizer de Hall (2006). Isso porque ao elegermos a temática "coordenação pedagógica x trabalho coletivo" como escopo reflexivo, remetemo-nos a uma miríade de experiências pedagógicas sistematicamente planejadas pela equipe de coordenadores pedagógicos com o objetivo de fortalecer os processos participativos nas dinâmicas do ensino, potencializar a aprendizagem pelo seu viés coletivo e ampliar o repertório teórico-prático referente ao trabalho deste profissional da educação.

Uma dessas experiências, conforme assinalou uma das coordenadoras pedagógicas da escola, foi desenvolvida no período de 2000 a 2003, nas escolas estaduais; o programa do Governo Federal denominava-se "Classes de Aceleração". A escola campo dessa pesquisa integrou-se à proposta durante o período citado. No

Projeto Pedagógico do programa, havia a figura de um coordenador que tinha como função auxiliar, mediar e articular as práticas didático-pedagógicas no âmbito coletivo. O projeto tomou como público-alvo alunos com o que, à época, denominava-se “distorção série/idade" e "dificuldades de aprendizagem”. O corpo docente, apesar das 
dificuldades encontradas com as turmas, sentia-se amparado e mais seguro, pois era o planejamento coletivo que regia as ações realizadas no cotidiano da sala de aula.

Tratava-se de uma iniciativa que visava a inclusão escolar por meio da organização e execução coletiva do trabalho pedagógico. Equipe docente, coordenação pedagógica e estudantes participavam mutuamente dos planejamentos, das avaliações, dos conselhos e demais instâncias que compunham o projeto. Dessa forma, o envolvimento e a integração dos indivíduos (coordenador/articulador, professores e alunos) construíam uma atmosfera pedagógica pautada no exercício da democracia, visando agenciar a cultura do aprender de modo participativo. A interação, o envolvimento, o autoconhecimento e o conhecimento mútuo contribuíam de modo muito singular na atribuição de sentido às práticas pedagógicas e no fomento da aprendizagem dos estudantes. Vejamos o que diz uma das coordenadoras pedagógicas que, à época, trabalhava no referido projeto:

Foi uma experiência diferenciada para todos os participantes, sem dúvidas. Os desafios eram muitos. Ao longo do projeto fomos nos dando conta de que, de fato, não sabíamos trabalhar em conjunto e de maneira interdisciplinar. A organização do currículo escolar tradicionalmente é muito fragmentada. Está posta de uma maneira que não inspira as trocas de experiências efetivas entre diferentes sujeitos, e nem de situações de ensino e de aprendizagem edificantes. Planejar as práticas pedagógicas, juntando estudantes e professores, por exemplo, era algo surreal. Eu sempre achava que aquilo não daria certo. Entretanto, aos poucos, fomos descobrindo a beleza, a grande viabilidade desse procedimento. Além de aproximar afetivamente as pessoas (professores, coordenadores, direção da escola, estudantes...), também desconstruía as hierarquias típicas da relação aluno x professor; parecia encher a prática pedagógica de sentido, tanto para alunos como para professores. Dali saíram muitas amizades e inesquecíveis experiências. Tenho conhecimento de alguns estudantes que já concluíram o ensino superior. Não que o projeto fosse perfeito. Não é isso. Mas gosto de salientar aquilo que foi significativo da experiência. Como coordenadora, aprendi a fazer com os outros e não para os outros. Foi um momento em que o meu trabalho parecia, de fato, ter algum sentido e produzir algum tipo de efeito em termos de qualificação das práticas de ensino e, especialmente, em termos de contribuição com o desenvolvimento dos alunos. (Comunicação oral, 2013.2) 
Nessa proposição, a ênfase da docência residia na promoção da legitimidade discente. Buscava-se afirmá-los como agentes do conhecimento. Havia, para contribuir com esse processo, o olhar atento e a presença ostensiva do articulador pedagógico, o qual exercia a importantíssima função de fomentar momentos de reflexão e planejamento coletivo que favorecessem a construção do sentimento de unidade entre a equipe pedagógica, bem como da postura solidária e cooperativa entre todos os sujeitos envolvidos nas tramas do projeto. Movimento ético, político e pedagógico que transversalizou todo o projeto e incidiu, sobremaneira, na qualidade do ensino, na permanência dos discentes no projeto e também no êxito em termos de aprendizagem.

\section{Coordenar o trabalho com os outros}

Por interessadas razões, neste artigo, optamos em concentrar nossa reflexão no seguinte foco: o lugar do coordenador pedagógico no fomento de trabalhos coletivos no ambiente escolar. Reiteramos que a opção temática feita por nós tem relação direta com os resultados do PI realizado na escola em que o projeto foi desenvolvido, entre $2013.1 \mathrm{e}$ 2014.2. Nesse período, tivemos acesso a indicadores que traduziam a seguinte realidade: a fragmentação das relações de ensino e de aprendizagem e a consequente necessidade de (re)aproximação dos sujeitos componentes dessa trama. Algumas pistas, tais como as narrativas de alguns professores e estudantes participantes do projeto e os registros dos coordenadores do projeto "Classe de Aceleração", indicavam que o coordenador pedagógico poderia ser um aliado singular na mediação de processo de construção de pontes afetivas ${ }^{2}$ junto à comunidade escolar.

Para tecer esse movimento reflexivo, elegemos alguns interlocutores teóricos que consideramos importantes parceiros na composição dessa escritura. Destacamos aqui

\footnotetext{
${ }^{2}$ Aqui buscamos ampliar a noção de afetividade, indo além do sentido psicológico clássico a ela atribuído. A partir de Deleuze (2002), e de sua inspiração na Ética de Espinosa, passamos a compreender afeto como sendo "toda força que toca um corpo e nele produção de movimento, alteração" (p. 56). Assim, quando um algo nos toca e entra em composição positiva com o nosso corpo, aumentando a nossa capacidade de agir, sentir e pensar, dizemos que experimentamos o afeto da alegria. Porém, quando o contrário nos acorre, dizemos que experimentamos o afeto da tristeza, e esta diminui a nossa potência de agir, pensar e sentir. A afetividade humana consistiria, portanto, nessa relação de reciprocidade com o mundo. Seria essa capacidade de afetarmos e sermos afetados pelo mundo, de sermos alterados pelas forças políticas, naturais e sociais e de também podermos alterá-las.
} 
alguns deles: Nietzsche (1986), para o qual o homem precisa declinar para tornar-se o que

é. Para o filósofo alemão, o homem não é uma um objetivo e nem um fim, mas uma passagem: flecha que anseia a outra margem.

Orsolon (2010) concebe o coordenador como um dos agentes de transformação da/na escola; Garrido (2009) defende a ideia do trabalho coletivo articulado pelo coordenador pedagógico; já Placco (2009), acredita em uma prática permanente de formação do coletivo com a atuação do coordenador pedagógico na escola. Esses autores nos provocam repensar e refletir sobre algumas questões importantes no ambiente escolar, principalmente a questão do planejamento coletivo como forma de qualificar e intensificar os processos de ensino e as dinâmicas afetivas da/na escola.

Por outro lado, percebemos que o sistema educacional/escolar contemporâneo caminha em passos lentos para uma mudança significativa no que diz respeito ao trabalho coletivo, havendo a necessidade de uma reflexão mais profunda em torno desse tema. A escola tem como objetivo formar sujeitos éticos, mas precisamos estar atentos a essas questões, pois a ação ética pressupõe, dentre outras coisas, a reflexão sobre a qualidade das relações interpessoais nas instituições e/ou para além delas. Como, então, instaurar uma atmosfera ética/humanística na escola, lugar privilegiado para o convívio coletivo? Eis novamente o sujeito foco da nossa discussão: o coordenador pedagógico. Parece-nos que ele se apresenta, ou pode se apresentar, como um sujeito implicado com a construção de experiências afirmadoras e qualificadoras das relações de afeto no ambiente escolar.

Lançar e ser flecha que almeja a outra margem das relações na escola. Cultivar bons afetos. Estimular o fortalecimento dos vínculos humanos. Incentivar movimentos solidários entre as pessoas. Articular a criação coletiva de estratégias didáticopedagógicas afirmadoras da aprendizagem de todos e de cada um. Instigar a composição de estratégias de uso da arte como recurso mediador das relações de ensino e de aprendizagem. Essas e tantas outras ações, incluindo aquelas que ainda não possuem nome e nem feição, pois estão situadas no campo das necessidades locais de cada particular tempo e espaço escolar, são apenas algumas possibilidades de frente de atuação que aqui vislumbramos como potenciais competências profissionais do 
coordenador pedagógico escolar. No nosso entendimento, o trabalho da coordenação pedagógica, para além das iniciativas burocráticas, como preenchimento do "sistema presença", secretaria escolar, produção de indicadores numéricos (sem leitura qualitativa) sobre evasão escolar, está situado, fundamentalmente, no campo das relações humanas. Campo ético, político e pedagógico por assim dizer.

Ao analisarmos essa questão, percebemos que este era um dos principais dilemas vividos na escola campo de desenvolvimento da pesquisa-intervenção. A dificuldade nas relações interpessoais e seus efeitos sobre a potencialização da aprendizagem dos estudantes ganhava relevo na escola, sobretudo por que havia instaurado no imaginário coletivo da escola uma perspectiva pedagógica que alimentava expectativa de que a aprendizagem ocorreria por um viés individualizado e conteudista. A maioria dos envolvidos não demonstrara uma compreensão de aprendizagem como processo humano e relacional, que se dá entre os sujeitos e as relações que estabelecem entre si e com os objetos a serem conhecidos. A coordenação pedagógica também apresentava dificuldades em atuar no fortalecimento das relações afetivas com o grupo de professores, os quais estavam, de certa forma, desacreditados. Especialmente no sentido de produção de mudanças.

\section{Percurso metodológico}

O percurso metodológico de desenvolvimento dessa pesquisa teve como ponto de partida o planejamento do Projeto de Intervenção (PI), que ocorreu, inicialmente, por meio da explanação dos objetivos do trabalho à direção da escola, às coordenadoras pedagógicas e aos professore/as Em seguida, aplicamos um questionário ao corpo docente, abordando questões referentes aos coordenadores pedagógicos da escola, com a intenção de verificar como os professores percebiam o coordenador em sua função na escola.

Ao aplicarmos o questionário aos professores, observamos que sentiam a necessidade de um apoiar o outro, mas não sabiam por onde começar. Alguns, em conversas informais, comentavam a questão de a coordenação estar um pouco distante 
das atividades realizadas em sala de aula, não podendo assim dar o apoio que seria necessário para o processo de ensino-aprendizagem. Dessa forma, surgiu a oportunidade de propor a aplicação de um projeto de intervenção que pudesse dar suporte para um planejamento coletivo, que foi feito através de um workshop 3 destinado à explicitação da importância do trabalho coletivo na escola e do apontamento de algumas possibilidades de contribuição do coordenador pedagógico na ampliação e intensificação dos processos de ensino e de aprendizagem.

$\mathrm{Na}$ sequência, ocorreram reuniões de planejamento. Dessa maneira, os professores tiveram um momento para rever suas práticas pedagógicas com o intuito de (re)pensá-las de forma que o trabalho coletivo preponderasse e fosse o instrumento para uma maior qualificação do ensino. No entanto, vemos que houve um distanciamento no que se refere ao trabalho coletivo, pois muitos professores sentiram-se inseguros diante dessa prática, necessitando, nesse momento, da intervenção assídua das coordenadoras pedagógicas para auxiliá-los. Isso no remete às ideias de Pires (2004) a respeito das possíveis funções da coordenação pedagógica escolar. Vejamos:

A função primeira do coordenador pedagógico é planejar e acompanhar a execução de todo o processo didático-pedagógico da instituição, tarefa de importância primordial e de inegável responsabilidade e que encerra todas as possibilidades como também os limites da atuação desse profissional. Quanto mais este profissional se voltar para as ações que justificam e configuram a sua especificidade, maior também será o seu espaço de atuação. Em contrapartida, o distanciamento dessas atribuições seja por qual motivo for, irá aumentar a discordância e desconhecimento quanto às suas funções e ao seu papel na instituição escolar. (PIRES, 2004, p. 182)

Seguindo essa reflexão proposta pelo autor, percebemos o quanto se faz necessário que o coordenador construa seu campo de atuação no ambiente escolar para que possa desempenhar o seu papel propositivamente. Ao fazermos uma análise

\footnotetext{
${ }^{3}$ Tratou-se do primeiro encontro com a direção e os/as coordenadores/as pedagógicos/as da escola em que a pesquisa ocorreu. Buscou-se, com essa experiência, iniciar o processo de aproximação com a realidade da pesquisa, bem como apresentar os objetivos da pesquisa e levantar possíveis necessidades e sugestões dos/as profissionais.
} 
qualitativa - levando em consideração dados como: estratégia de desenvolvimento do trabalho cotidiano do coordenador pedagógico, principais empecilhos na execução das tarefas, pontos de vista dos docentes e discentes em relação ao trabalho deste profissional, e as dificuldades e êxitos experimentados no período em que o estudo foi desenvolvido -, reiteramos que o trabalho coletivo, mediado pelo coordenador pedagógico, é ainda um desafio a ser superado. Ou seria essa a natureza do seu ofício: o desassossego? O constante deslocamento de lugar? Um meio e não um fim? Talvez uma inteligibilidade fundamental a esse respeito nos seja sugerida por Guimarães Rosa (2001), pois para o poeta do Grande Sertão "o real não está nem na chegada e nem na partida, mas no meio: na travessia" (ROSA, 2001, p. 287). Aproximar-se desse raciocínio literário associando-o ao ofício do coordenador pedagógico, implica em concebê-lo como movimento dialético, e, portanto, constituído por tensões, por múltiplos jogos de forças e acontecimentos. Sobretudo porque se trata de uma prática profissional eminentemente situada nos domínios das subjetivações, isto é, da formação humana, e ambos são processos políticos, históricos e pedagógicos.

Diante do exposto, podemos refletir sobre o tema através de alguns questionamentos, os quais sejam: como o coordenador pedagógico lida com as dificuldades encontradas na escola com relação às práticas pedagógicas do corpo docente? Que significado a comunidade escolar atribui ao trabalho do coordenador pedagógico? Quais seriam as possibilidades favorecedoras do trabalho coletivo na escola? Entendemos que estas questões são bastante pertinentes para a ampliação e complexificação do debate sobre o trabalho do coordenador pedagógico no contexto escolar. Elas balizarão, ainda que provisoriamente, as reflexões urdidas no seguimento desse artigo.

\section{Cotidianidade escolar: dilemas, impasses e ações inventivas}

É preciso compreender que as dificuldades encontradas no espaço escolar, por parte dos profissionais da educação, são muitas e complexas. A escola é um ambiente atravessado pelas tramas sociais, pelos contatos afetivos, por conflitos, pelos 
intercâmbios e hierarquias culturais, por violências, por vetores políticos e econômicos, por distintas condições intelectuais, por relações de poder, por perspectivas ideológicas, dentre outros atravessamentos. Essas e tantas outras singularidades fundam a vida escolar pela alteridade radical (DERRIDA, 2004). A diferença, a desigualdade e a singularidade, assim, estão na gênese do tecido formador do corpo da escola. A escola, como uma das representantes de um estado de direito, tem o dever de assegurar e edificar políticas pedagógicas que reconheçam as diferenças e legitimem as singularidades, que denunciem e se contraponham a toda e qualquer forma de exclusão e de hierarquização das relações. Como, então, inventar práticas e relações afirmativas das necessidades de todos e de cada um? Que iniciativas e desafios podem ser assumidos pelo coordenador pedagógico na busca pela afirmação de novos estilos de convivência na escola? Que relações esses canônicos paradigmas possuem entre si e que efeitos produzem sobre a organização e o funcionamento do cotidiano da escola? O fomento de práticas pedagógicas coletivas seria um mecanismo de resistência à cultura escolar estéril que classifica, rotula, coage e marginaliza os corpos em termos de sanidade e legitimidade?

Não pretendemos esgotar todas essas perguntas no sentido de respondê-las, porém desejamos construir inteligibilidades possíveis sobre algumas delas. Assim, teceremos reflexões que consideramos pertinentes na relação com as problemáticas levantadas. Na sequência, apresentaremos algumas pistas sobre o contexto escolar campo da pesquisa. Com isso, desejamos melhor situar no tempo e no espaço o cenário e os sujeitos participantes da pesquisa. Iniciamos pelas coordenadoras pedagógicas, que são chamadas de Assistentes Técnico-Pedagógicas (ATP). Aqui elas serão nomeadas como "ATP 1" e "ATP 2". A ATP 1 trabalha na educação há 22 anos e há oito anos atua como Assistente Técnico-Pedagógica na escola campo da nossa pesquisa- intervenção; tem 55 anos e possui formação em Pedagogia. A ATP 2 trabalha na educação há oito anos, quando assumiu as atividades de Assistente Técnico-Pedagógica. É formada em Letras e leciona no Centro de Educação de Jovens e Adultos no contraturno; não tem experiência no ensino regular como professora. Antes de assumir as atividades na escola, 
trabalhou como secretária num escritório de contabilidade por longa data. Tem 45 anos de idade.

Nesse cenário, podemos analisar alguns depoimentos das coordenadoras pedagógicas relatados no início do projeto de intervenção. A ATP 1 e ATP 2 fazem as seguintes afirmações:

Passamos o dia todo resolvendo problemas burocráticos, mas necessários para o bom andamento escolar. Atuamos, entretanto, na solidão. Sem elos com a rede pedagógica interna da escola, sem parcerias". Complementou, ainda, [...] é um trabalho pouco ou não reconhecido pela comunidade escolar. (ATP - 1)

Deveríamos trabalhar mais em prol da aprendizagem dos discentes, mas, devido ao pouco tempo e pouca formação acerca do papel do coordenador pedagógico na escola, não nos sentimos à vontade para adentrar nesse espaço. (ATP - 2) (Diário de campo, 2013.2)

Podemos perceber, no seu depoimento, que as coordenadoras pedagógicas cumprem com a função que Ihes foi incumbida na contratação, isto é, a de Assistente Técnico-Pedagógica ${ }^{4}$. Por outro lado, percebemos que a função que a escola espera desse profissional é distinta, ou seja, espera-se que ele seja polivalente ("faz tudo"). Atualmente, na escola campo da pesquisa, este profissional é frequentemente solicitado a auxiliar a busca por solução de problemas que emergem no cotidiano escolar. Via de regra, é a ele a quem os professores recorrem quando encontram algum problema com os alunos, seja de aprendizagem ou indisciplina e conflitos de natureza interpessoal. $\mathrm{O}$

\footnotetext{
${ }^{4}$ O Assistente Técnico-Pedagógico da Rede Estadual de Educação de Santa Catarina - SC; é o Servidor Público da área de Educação. Tem como atribuições, participar de estudos e pesquisas de natureza técnica sobre administração geral e especifica e na elaboração de programas para o levantamento, implantação e controle das práticas de pessoal. Desenvolve e auxilia atividades relativas aos segmentos envolvidos diretamente com o processo ensino-aprendizagem. A Lei Complementar 288/2005 acrescentou novas atribuições a este profissional, tais como: auxiliar na distribuição dos recursos humanos, físicos e materiais disponíveis na escola; participação no planejamento curricular; participa dos conselhos de classe, reuniões pedagógicas e grupos de estudo; deve também auxiliar na administração e organização das bibliotecas escolares e executar outras atividades de acordo com as necessidades da escola.
} 
que essa aparente falta de sincronia entre esses profissionais pode revelar sobre a natureza do trabalho do coordenador pedagógico? Seria ele tomado como uma espécie de "algoz" de problemas da escola que são de responsabilidade coletiva? No quadro funcional da escola, seria uma espécie de "bode expiatório" representante de sintomas intersetoriais que transversalizam, micro e macropoliticamente, o Sistema Educacional?

Seguindo as pistas oferecidas pelas vozes das coordenadoras pedagógicas participantes dessa pesquisa, podemos observar certo distanciamento deste profissional do processo educacional propriamente dito. Isso porque, na sua visão, o corpo docente, a gestão escolar e a própria coordenação pedagógica ainda trabalham de forma isolada e fragmentada. Isso nos sugere que dentre os desafios que o coordenador tem como horizonte, figura a tarefa de composição de pontes afetivas e setoriais na escola. Pontes que afetem a lógica disciplinar da escola, resistindo-a e desconstruindo-a. Isso nos leva a refletir com Pimenta (1991) quando afirma que:

Nesta tentativa de traduzir a competência da equipe pedagógica, fica claramente evidenciado o significado de trabalho coletivo na escola - não é possível trabalhar fragmentadamente o objeto do trabalho da Escola, não dá e não é desejável estabelecer fronteiras claramente delimitadas sobre o que compete a quem, mas dá para identificar claramente que este trabalho precisa de competências específicas.(PIMENTA, 1991, p. 82)

A partir disso constatamos que - devido à precarização do processo formativo do coordenador pedagógico, à ilegitimação da sua função na escola, e, sobretudo pelo sincretismo vinculado ao seu trabalho - este profissional tende a exercer apenas atividades de teor burocrático como forma de atribuir algum tipo de sentido ao seu exercício profissional. Entretanto, este subterfúgio tende a despotencializá-lo em termos profissionalizantes. A insatisfação, o embotamento do desejo, a frustração profissional e a consequente obsoletização do seu enquadre profissional tornam-se efeitos imediatos desse decadente movimento. Os trabalhos burocráticos diários com os quais se envolve, tendem a sucumbir a identidade profissional do coordenador pedagógico escolar. 
Nesse sentido, podemos perceber que o coordenador pedagógico procura (re)construir seu espaço de atuação profissional e tenta legitimar o seu papel no âmbito escolar. Mas essa busca parece-nos bastante sinuosa e complexa. Sendo que, por vezes, ante aos obstáculos encontrados, ele é acometido por inseguranças e temores que o ameaçam e nele produzem paralisias. Acreditamos que esse caminhar aparentemente trôpego não é exclusividade deste profissional na escola. Talvez ele seja apenas o representante escolhido pela cultura da escola para expressar um sintoma generalizado. Portanto, tomar tal situação como sua responsabilidade específica seria uma atitude equivocada. Assim, descomprometê-lo dela seria ainda outra atitude controversa. Eis um paradoxo!

Faz-se necessário, todavia, compreender que a escola é um microssistema enredado nas tramas do sistema societal. Acompanhar as mudanças do sistema capitalista globalizado e compreender como elas incidem sobre a vida e sobre o trabalho na escola é necessário. Compreender ainda a complexidade do sistema e das políticas educacionais, da macro à microestrutura, a nosso ver, também pode ser uma tarefa fortalecedora da identidade do coordenador pedagógico. Para muito além da atuação burocrática, seu trabalho precisa assumir uma natureza política. Articular movimentos políticos para constituir processos de ensino éticos e, assim, fomentar movimentos de aprendizagem emancipatórias na escola contemporânea, parece-nos ser o mais caro desafio a ser assumido ante a "crise" identitária que vive este profissional da educação. Essa reviravolta em termos de concepção do seu ofício parece coincidir com o desenfreado movimento da própria vida. Afinal, como o próprio Nietzsche (1986) já nos ensinou: é preciso ter caos dentro se si para se fazer nascer uma estrela brilhante.

\section{Descortinando olhares: a Comunidade Escolar e os seus modos de ver}

Consideramos a importância que o coordenador pedagógico tem no ambiente escolar, principalmente como articulador de práticas coletivas no processo ensinoaprendizagem. No entanto, será que todos os sujeitos que fazem parte da escola veem as coordenadoras pedagógicas como profissionais importantes no processo educacional? 
Esse questionamento nos faz refletir sobre alguns depoimentos de colegas professores durante o período de aplicação do PI, pois, ao pensar em planejamento coletivo, todos foram favoráveis, principalmente no dia em que lhes foi apresentado o projeto de intervenção pelas pesquisadoras do Curso de Especialização em Coordenação Pedagógica; mas ao perceberem que o trabalho coletivo seria articulado pelas ATPs da escola, a postura dos professores foi outra. Nossa hipótese é que o movimento de recusa na participação do projeto, por parte dos docentes, ocorreu, conforme seus próprios relatos, em razão da descrença por eles atribuída à figura e ao trabalho do coordenador pedagógico.

Isso nos reporta a um dado momento em que uma professora nos perguntou quando começaríamos as reuniões de planejamento. Ao explicarmos que essa ação seria conduzida pelas coordenadoras, percebemos que ela perdeu o interesse pelo projeto, pois parecia não acreditar mais que esse sairia do papel. Acreditamos que tal descrédito advém do próprio histórico que o ATP traz consigo, pois é contratado para uma determinada função, isto é, a de Assistente Técnico-Pedagógico, entretanto, quando chega à instituição, via de regra, é alocado na função de coordenador pedagógico ${ }^{5}$.

Nesse propósito, a própria coordenadora pedagógica (ATP 2) nos relatou que quando chegou à escola estava toda animada, cheia de planos e ideias para o novo trabalho, mas logo foi barrada por uma professora efetiva da escola, a qual lhe disse que ela não tinha experiência em sala de aula e não poderia opinar sobre tal prática. Isso fez com que a ATP 2 se retraísse e não avançasse mais em questões pedagógicas. Essas falas são frequentes nas escolas, pois ouvimos, muitas vezes, os professores reclamarem que ninguém faz nada no ambiente escolar quando ocorre algum problema um pouco mais sério. Certamente, ao falar isso se referem à direção escolar e principalmente ao coordenador pedagógico.

\footnotetext{
${ }^{5}$ Para melhor compreender essas questões, uma das alternativas parece-nos ser o investimento em linhas de pesquisas que investiguem a relação entre os cursos de Pedagogia e demais licenciaturas no próprio contexto da formação universitária e suas (não) ênfases no debate sobre o trabalho do Assistente Técnico Pedagógico e do Coordenador Pedagógico. Outro eixo de investigação, do nosso ponto de vista, poderia ser a relação entre diferentes carreiras tanto no contexto do ensino fundamental quanto do superior.
} 
Desse modo, percebemos que o coordenador é passivo de julgamentos e tende a perder as forças para mediar o coletivo da escola. São tantos os entraves que ele acaba se excluindo do grupo, desenvolvendo simples trabalhos burocráticos e toda a equipe perde com essa atitude, pois ao falarmos em coletividade, todos os sujeitos envolvidos no processo têm sua função a desempenhar, e são necessários para o desenvolvimento das ações, tendo em vista que o sucesso depende de todos.

Nessa perspectiva, entramos no campo das relações interpessoais e precisamos deixar de lado nossos saberes individuais para formamos um saber coletivo pelo coletivo. Esse é nosso maior desafio: conceber o coordenador pedagógico como um sujeito capaz de contribuir no processo ensino e aprendizagem, sobretudo no que diz respeito à função de mediar práticas coletivas.

\section{Articulação pedagógica como ato criador: pistas e possibilidades}

Quando analisamos a realidade das escolas públicas, a qual é o nosso foco neste estudo, em particular da escola campo da pesquisa, percebemos que (re)criar significados para as práticas coletivas é um grande desafio a ser superado. Esta é uma tarefa que também precisa ser estendida para o corpo docente e para a gestão escolar. O fomento da cultura da participação e da consequente politização dos processos pedagógicos é uma tarefa a ser assumida por todos. Ao coordenador pedagógico, caberia, ainda que não exclusivamente, fazer o acompanhamento e investir na manutenção de: situações pedagógicas que favoreçam a criação de pontes entre conhecimento e vida; iniciativas destinadas à desconstrução de muros simbólicos geradores de apartheid's culturais e disciplinares; ações de incentivadoras do prestígio e da valorização do outro; práticas de cultivo da cultura de paz na escola; projetos voltados para a formação política da comunidade escolar.

Ao encerrarmos o PI, ficaram bastante evidentes para nós as dificuldades de articulação e mediação do trabalho coletivo no cotidiano escolar enfrentadas pelo coordenador pedagógico. Após a avaliação dos trabalhos e da reflexão acerca do tema, 
percebemos a importância e a necessidade de um estudo mais aprofundado sobre caminhos e possibilidades para concretizar um trabalho coletivo nessa escola.

Dessa forma, percebemos que a construção do fazer coletivo tem relação com uma série de atitudes, envolvendo os indivíduos em questão, como a participação, a colaboração, o querer, a tomada de decisões, o arriscar-se, a partilha, a solidariedade e o compromisso. Com toda essa abrangência, essa empreitada parece se tornar um tanto assustadora aos olhos das pessoas, pois entramos no campo complexo que envolve cultura, valores, formação específica do professor e concepções educacionais.

A partir dessa reflexão, podemos afirmar que para o trabalho coletivo efetivamente ocorrer, precisamos ser solidários uns com os outros no sentido de cooperação. Assim, a ideia de alguém pode ser tão boa a ponto de ser aceita pelos colegas e ainda melhorada por eles. Essa é a beleza do trabalho coletivo: a construção coletiva do desejo de saber. É o crescimento mútuo dos indivíduos no processo, sejam eles alunos, professores, gestores ou coordenadores pedagógicos. Aliás, para Deleuze e Guattari (1996) o desejo tem poder revolucionário. Segundo os autores, o desejo é o sistema de signos com os quais se produzem fluxos de inconsciente em um campo social. “Não há eclosão alguma de desejo, em qualquer lugar que seja, pequena família ou escola de bairro que não questione as estruturas estabelecidas. O desejo é revolucionário porque quer sempre mais conexões e agenciamentos" (p. 64).

Assim sendo, precisamos ficar atentos, pois o não querer nem sempre denota falta de vontade ou não comprometimento, mas possivelmente também insegurança quanto ao novo. O trabalho burocrático e repetitivo, como já anunciado, oblitera os fluxos do desejo. O que nos torna, por sua vez, prisioneiros da mesmidade pedagógica, política, social, e, por que não dizer: existencial. A produção de sentido no fazer e no viver cotidiano da escola tornar-se-á um horizonte alcançável se os fluxos do desejo forem viabilizados nas experiências na escola. Eles precisam ser os representantes da vida que corre e que é flecha que almeja o outro lado do abismo. A vida não cessa de metamorfosear-se. Tal como a arte, ela quer sempre assumir novos estados e feições. $\mathrm{Na}$ escola, assim como nas instituições em geral, cada vez mais é necessária a produção de ações comprometidas com a libertação da vida lá onde ela é prisioneira: da burocracia, do 
disciplinamento, da indiferença, do estado, da vaidade, das hierarquias, da melancolia, enfim, de tudo que obstrui os fluxos do viver individual e coletivo na escola e fora dela.

Refletir a respeito das relações e dos atravessamentos desejantes parece fazer sentido ante a uma realidade escolar empalidecida e minguada em termos vitais. A busca pelo respeito e pelo diálogo entre o corpo docente, coordenadores pedagógicos, gestão escolar, educandos, pais e outros funcionários da escola é uma necessidade, uma meta a ser superada todos os dias. Desobstruir o fluxo do desejo nessas relações é resistir aos imperativos de uma cultura escolar estéril que coage, censura, constrange, corrói e mortifica os corpos em suas mais tenras necessidades vitais.

A confiança, o respeito e a vontade de ensinar e aprender podem ser reestabelecidas com ações implicadas com a afirmação da vida. E, para nós, a vida é sinônimo de inventividade, mistério, movimento, suavidade, eclosão... A vida quer sempre ir além, é vontade de potência (NIETZSCHE, 1986). Ela nos afeiçoa com seus paradoxos. Portanto, um trabalho pedagógico eticamente comprometido, assume a vida como critério inegociável. É necessário aprender a assumi-la com tudo que ela abarca, sem exceção. Para tanto, é preciso valentia. Amor fati, num dizer nietzscheano.

Nessa ótica, um olhar sensível voltado às necessidades do outro se constrói, pois, quando superamos a cultura da exceção. Quando acolhemos o outro na sua inteireza, na radicalidade do seu ser-viver. "Quando alguém é ouvido (e compreendido), isso traz uma mudança na percepção de si mesmo, por sentir-se valorizado e aceito. E, por sentir-se valorizado e aceito pode apresentar-se ao outro sem medo, sem constrangimentos" (ALMEIDA, 2011, p. 79).

Assim, podemos afirmar que o estabelecimento de relação de confiança é um dos mais emblemáticos problemas que acometem o cotidiano da escola. Ao atuar nos meandros das relações, fomentando a irrigação e a afirmação da vida por meio da desobstrução dos fluxos do desejo, o coordenador pedagógico abre fissuras em regiões sedimentadas pela história de um tipo de pedagogia enfastiada. Trilhar novos caminhos pedagógicos e fender os solos áridos da educação são tarefas amplas e complexas que implicam no despojamento das visões universais e ímpetos imediatistas. Isso exigirá o 
investimento na criação de um tipo distinto de aprendizagem, como por exemplo, aquele que se pauta na construção de projetos coletivizados que visa contribuir para a construção de um saber-ser-fazer marcado, na sua gênese, pelos princípios da ética, da solidariedade e da participação democrática.

\section{Derradeiras considerações}

Com o intuito de construir inteligibilidades sobre as vicissitudes do trabalho coletivo na referida escola, bem como criar reflexões que inspirem a sua promoção, lançamos às coordenadoras pedagógicas o projeto de intervenção, na ingênua ideia de que seria um trabalho fácil para ambas as partes. Nesse momento, destacamos a importância do coordenador pedagógico no ambiente escolar e a importância de se trabalhar com projetos educacionais. No decorrer do processo de pesquisa e intervenção, percebemos o quanto esse tema nos remetia a grandes reflexões e grandes questionamentos. Quem são as personagens em questão? Como se veem e como são vistas pela comunidade escolar? Como lidam com medos, inseguranças e desafios?

Diante desses questionamentos, buscamos no referencial teórico autores que nos dessem os aportes para fomentar a discussão. Isso tornou possível a investidura numa reflexão mais aprofundada acerca do cotidiano escolar, do trabalho na coletividade, e, principalmente, sobre a natureza complexa do ofício do coordenador pedagógico escolar. O que não significa dizer, entretanto, que todas as perguntas foram respondidas em sua totalidade. Isso porque na medida em que ensaiamos possíveis respostas às questões levantadas, outras perguntas foram surgindo.

Com este estudo, construiu-se a compreensão de que não basta ancorar a função do coordenador pedagógico na correlação "mediar x articular”. Parece-nos que seu papel é mais amplo e complexo, e envolve ações de natureza ética, política e pedagógica comprometidas com processos de democratização do saber, do ensinar e do viver coletivo. Entretanto, como não se trata da convicção de que aqui tudo foi dito sobre o foco dessa reflexão, cabe-nos dizer que este artigo mais abriu questões do que fechou. 
Destacamos, assim, a necessidade de maiores investimentos em pesquisas que investiguem o processo formativo dos diferentes profissionais da área da educação, bem como sobre os processos de institucionalização de suas práticas na cena educacional. No caso do trabalho do coordenador pedagógico escolar, encontramos uma miríade de dilemas, contradições e incertezas que atuam na contramão do processo de legitimação, caracterização e afirmação político-pedagógica do seu ofício.

\section{Referências}

DELEUZE, Gilles. Diferença e repetição. Rio de Janeiro: Graal, 2006.

DELEUZE, Gilles; GUATARRI, Félix. Mil Platôs: capitalismo e esquizofrenia, vol. 1/. Tradução de Aurélio Guerra Neto et al. São Paulo: Ed. 34, 1996.

GARRIDO, Elsa. Espaço de formação continuada para professor-coordenador. In: ALMEIDA, Laurinda Ramalho de; BRUNO,Luiza Helena da Silva (Orgs.). O coordenador pedagógico e a formação docente. São Paulo: Loyola, 2009.

HALL, Stuart. Da diáspora: identidades e mediações culturais. Belo Horizonte/Brasília: Editora UFMG/Unesco, 2006.

NIETZSCHE, Friedrich. Assim falou Zaratustra: um livro para todos e para ninguém. Trad. Mário da Silva. Rio de Janeiro: Civilização Brasiliense, 1986.

ORSOLON, Luzia Angelina Marino. O coordenador/formador como um dos agentes de transformação da/na escola. In: ALMEIDA, Laurinda Ramalho de; PLACCO, Vera Maria Nigro de Souza (Orgs.). O coordenador pedagógico e o espaço da mudança. São Paulo: Loyola, 2010.

PIMENTA, Selma Garrido. O pedagogo na escola pública. 2. Ed. São Paulo: Loyola,1991.

PIRES, Ennia Débora Passos Braga. A prática do coordenador pedagógico:limites e perspectivas, 2004 Dissertação, (Mestrado em Educação) - Universidade Estadual de Campinas, Faculdade de Educação, Campinas, , 2004.

PLACCO, Vera Maria Nigro de Souza; SILVA, Sylvia Helena Souza da. A formação do professor: reflexões, desafios, perspectivas. In: BRUNO, Eliane Bambini Gorgueira; ALMEIDA, Laurinda Ramalho de; CHRISTOV, Luiza Helena da Silva (Org.). O coordenador pedagógico e a formação docente. São Paulo: Loyola, 2009. 
PLACCO, Vera Maria Nigro de Souza. O coordenador pedagógico e os desafios da educação. São Paulo; Loyola, 2009.

ROSA, João Guimarães. Grande sertão: veredas. $19^{\mathrm{a}}$ ed. Rio de Janeiro: Nova Fronteira, 2001. 